\title{
Gênero, emoções, afetos e cuidados: novos desafios para o campo da filosofia
}

\author{
Mateus Gustavo Coelho ${ }^{1}$
}

Cristina Scheibe Wolff ${ }^{2}$

\begin{abstract}
Resumo: Este trabalho pretende traçar uma relação entre a recente abertura acadêmica da Filosofia para os estudos feministas no Brasil e de como estes, em grande parte, têm sido responsáveis por colocar novos desafios ao ato de filosofar a partir das possibilidades trazidas pela discussão das interações entre a categoria gênero, com os estudos de afetos, emoções e cuidado. Ao trazer os afetos e emoções, ligados ao gênero, para a discussão nas Ciências Humanas e na Filosofia, os estudos feministas buscam estabelecer relações com partes da vida humana que durante séculos foram deixadas de lado no pensamento filosófico. Temas como a relevância das emoções, o cuidado com o outro e os afetos cada vez mais se fazem presentes dentro dos espaços de debate. Os estudos feministas não apenas ampliaram as temáticas possíveis dentro da academia, como também propiciaram diferentes possibilidades de escrita ao dar ênfase às subjetividades. Partindo de uma análise bibliográfica de autoras que pesquisam o papel dos afetos, emoções e cuidados, defendemos aqui que os estudos feministas ao trazerem estes temas como categorias de análise trazem consigo o próprio ato de espantar-se e de afetar-se com o mundo.
\end{abstract}

Palavra-chave: Gênero - Filosofia - Feminismos - Campos discursivos - Espanto

\section{Gender, emotions, affections and care: new challenges for philosophy}

\begin{abstract}
This work intends to trace a relationship between the recent academic opening of Philosophy to feminist studies in Brazil and how these, in large part, have been responsible for posing new challenges to the act of philosophizing from the possibilities brought by the discussion of the interactions between gender, affections, emotions and care studies. Bringing affections and emotions linked to gender to the discussion in Human Sciences and Philosophy, feminist studies seek to establish relationships with parts of human life that for centuries have been left aside in philosophical thought. Themes such as the relevance of emotions, care and affections are increasingly present within the spaces of debate. Feminist studies have not only expanded the possible themes within academia, but have also provided different possibilities for writing by emphasizing subjectivities. Starting from a bibliographic analysis of authors who research the role of affections, emotions and care, we argue here that feminist studies when bringing these themes as categories of analysis bring with them the very act of being wondered and affected with the world.
\end{abstract}

Keywords: Gender - Philosophy - Feminism - Discursive fields - Wonder

\footnotetext{
${ }^{1}$ Doutorando no Programa Interdisciplinar em Ciências Humanas da Universidade Federal de Santa Catarina, Florianópolis, SC, Brasil. E-mail: mateusgusco@gmail.com.

2 Professora titular do Departamento de História da Universidade Federal de Santa Catarina, Florianópolis, SC, Brasil. E-mail: cristiwolff@gmail.com.
} 


\section{Introdução: as origens do ato de filosofar}

O que é próprio da Filosofia? Em um primeiro momento, esta pergunta pode parecer impossível de ser respondida. A Filosofia é a área do conhecimento que nunca esteve atrelada a apenas um conteúdo específico e, é justamente por esta característica que está em sua constituição buscar as questões que parecem ser impossíveis de serem respondidas. Mas antes de moldar-se enquanto área do conhecimento, a Filosofia parte de uma postura em relação ao mundo. Antes de ser uma disciplina formatada nos moldes acadêmicos, temos a maneira como quem faz a Filosofia se posiciona diante do mundo. Esta maneira chamamos de "ato de filosofar", uma forma abstrata, quase metafísica de estar absorto pelo real. Assim, antes de falarmos da Filosofia, temos como meta buscar uma maneira de responder a seguinte questão: "em que consiste o 'ato de filosofar'?".

Novamente, temos em mãos uma pergunta difícil de ser respondida. Desde os primórdios da humanidade, perguntas em relação ao mundo são feitas. Homens e mulheres procuram respostas às mais variadas questões. Portanto, o "ato de filosofar" sempre esteve presente na história da humanidade. No mundo grego, entendia-se que a origem do

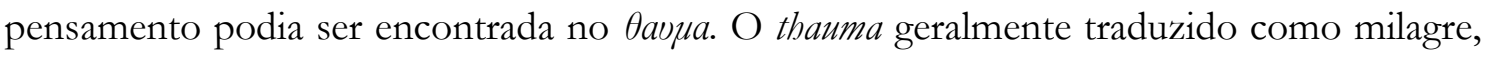
no pensamento clássico foi compreendido como a capacidade de se espantar com o mundo, de se admirar ou se maravilhar com o que nos circunda. Para Sócrates, o "ato de filosofar" nasce do espanto, do admirar-se com tudo aquilo que ainda não conhecemos. No diálogo Teeteto, ele afirma ${ }^{3}$ :

Estou vendo, amigo, que Teodoro não ajuizou erradamente tua natureza, pois a admiração é a verdadeira característica do filósofo. Não tem outra origem a filosofia. Ao que parece, não foi mau genealogista quem disse que Íris era filha de Taumante [.... ${ }^{4}$

Assim, encontramos no thauma o princípio fundamental para começar a filosofar. É o espanto que nos coloca em movimento em busca ao conhecimento, é o surgimento da consciência que se dá de forma quase que milagrosa e é parte constituinte da humanidade.

\section{Mito e Filosofia: as origens do pensamento racional filosófico}

Diferentemente do "ato de filosofar", que está presente desde o surgimento da humanidade, a filosofia, enquanto disciplina ${ }^{5}$, possui uma data e um local de surgimento. Para

\footnotetext{
${ }^{3}$ Entendemos a diferença entre a figura histórica de Sócrates e a personagem socrática desenvolvida nos textos de Platão. Neste trabalho, utilizamos esta passagem apenas como uma alegoria que se cristalizou na cultura ocidental como sendo o pensamento socrático.

4 PLATÃO, Diálogos: Teeteto, p. 37.

${ }^{5}$ Entendemos aqui como Filosofia disciplinar um campo do conhecimento que parte de um pensamento organizado e conceitual dado a partir de um método específico. Assim, diferentemente do que entendemos como "ato de filosofar", ou seja, o ato de espantar-se e indagar-se sobre o mundo, a Filosofia disciplinar se caracteriza por suas escolhas. Durante toda a história do pensamento ocidental, a Filosofia selecionou certos problemas privilegiando questões e discriminando outras, construindo um discurso de exclusão e, muitas vezes, de desqualificação sistemática de outras formas de pensar o mundo. A partir de uma suposta "generalidade" e "neutralidade" a Filosofia disciplinar produz o seu sujeito epistêmico por excelência, ou seja, um sujeito masculino, branco e heterossexual, em geral americano ou europeu, em detrimento de todos os outros.
} 
o classicista escocês John Burnet (1863-1928), a Filosofia nasce quando as explicações míticas da realidade já não conseguem dar conta do real, assim o mito é deixado de lado dando lugar à racionalização filosófica. Para ele, a Filosofia só surge quando a visão tradicional do mundo e as regras costumeiras são quebradas, só após esta ruptura os gregos começaram a sentir as necessidades que as filosofias da natureza e da conduta procuram satisfazer ${ }^{6}$. Neste modelo, a Filosofia só pode surgir com a ruptura completa com o mito. Assim, o pensamento filosófico só poderia aparecer numa região onde não houvesse ou houvesse pouca influência da mitologia. A partir do pensamento de Burnet, Filosofia e mito se tornam opostos não podendo coexistir em um mesmo local.

Por outro lado, surge a linha de pensamento proposta pelo estudioso clássico inglês Francis Macdonald Cornford (1874-1943). Segundo ele, a estrutura dos Mitos está presente na Filosofia, ou seja, os filósofos não apenas fazem um uso dos termos da mitologia, mas efetuam um empréstimo conceitual. Desta maneira, a notável explosão de especulação abstrata entre os pensadores pré-socráticos do século VI a.C. surgiu diretamente do pensamento religioso da era anterior na Grécia, rejeitando a suposição racionalista de que a religião e a Filosofia são fundamentalmente diferentes uma da outra. A religião se expressa em símbolos poéticos e em termos de personalidades míticas, já a Filosofia prefere a linguagem de abstrações secas e discursos sobre a substância, causa, matéria e assim por diante, mas a diferença exterior apenas disfarça uma afinidade interna e substancial entre esses dois produtos sucessivos de uma mesma consciência ${ }^{7}$.

O historiador e antropólogo francês Jean-Pierre Vernant (1914-2007) propõe romper com a dicotomia criada pela escola de pensamento britânica. Em sua teoria, na Filosofia o mito é racionalizado, ou seja, mito e Filosofia falam de um mesmo conteúdo, mas de maneiras diferentes, assim, ainda permanece muito do mito no pensamento filosófico.

Segundo Vernant, o pensamento racional tem data e lugar de nascimento, e é este nascimento da Filosofia na Grécia que marcaria o início do pensamento científico. Esta forma de pensar surge do contato com grandes civilizações orientais como a da Índia e a da China, desta forma, nosso conhecimento próprio do Ocidente deve muito às formas de pensar orientais. A Filosofia então seria uma forma abstrata e laicizada do sistema de representação que a religião elaborou. No processo em que surge a Filosofia na Grécia não houve a necessidade de criação de um sistema de explicação do mundo, pois os filósofos já o encontraram pronto, repetindo em uma linguagem diferente aquilo que o mito já dizia.

Hesíodo sistematiza o mito no mundo grego, mas mesmo com esta sistematização o

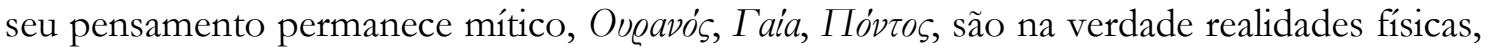
mas ao mesmo tempo forças divinas. Mas é entre os milésios, segundo Cornford, que Sxcavós e Taía despojaram-se de todo o aspecto antropomórfico para tornarem-se puramente a água e a terra, sendo forças ativas, divinas e naturais. Produzindo efeitos físicos determinados, estes que são sempre uma qualidade geral abstrata. O mundo dos jônicos, um mundo "cheio de deuses" é também um mundo "plenamente natural", pois tudo aquilo que é real é natureza, e a natureza, a $\Phi$ uøৎ é a força de vida e de movimento. É no domínio da physis que o mundo passa a ser visto como um mecanismo, esvaziando-se pouco a pouco do divino que o animava entre os primeiros físicos. Diferente do que acontece na jônia, é na

\footnotetext{
${ }^{6}$ BURNET, Early Greek Philosophy, p. 2.

${ }^{7}$ CORNFORD, From Religion to Philosophy: a Study in the Origins of Western Speculation, p. 5.
} 
Itália, na Magna Grécia, com os pitagóricos que a Filosofia deixa de evidenciar a unidade da $\Phi$ mesmo tempo religiosa e filosófica.

Infelizmente, a reconciliação entre mito e Filosofia feita por Vernant veio tarde demais. Durante milhares de anos, a Filosofia renegou seu lado mítico, ficando presa em um local que almejava uma exclusiva racionalidade, deixando de lado tudo aquilo que não se encaixa nestes padrões. Este espaço de privilégio da racionalidade deixou marcas profundas em nossa sociedade ocidental. A exacerbada valoração da racionalidade gerou seu espaço de alteridade, criando um "outro" no modelo beauvoariano, ou seja, aquilo que seria o oposto ao racional, constituindo-se como uma negação do racional.

\section{O pensamento dual e hierarquizado}

A filósofa francesa Hélène Cixous nos coloca que o pensamento sempre operou mediante oposições duais hierarquizadas ${ }^{8}$. Entre as principais dicotomias está a distinção entre $\log o s /$ pathos, deixando a racionalidade alheia às emoções. A compreensão do mundo a partir de hierarquias dicotômicas está nas bases de nossa sociedade como afirma a pensadora argentina María Lugones ${ }^{9}$, sendo a lógica categorial dicotômica e hierárquica central para o pensamento capitalista e colonial moderno. Esta lógica deixou marcas profundas na construção de nosso tecido social, deixando de um lado aqueles tidos como dominantes e do outro, os dominados. Assim, o homem enquanto sua imagem como "sexo forte" é tomado como o dominante relegando às mulheres o papel de dominadas. Para Coelho:

Ao se construir um ideal de masculino, deve-se ao mesmo tempo construir um ideal de feminino, este sendo uma negação do ideal dominante. (...) Esta construção tem suas bases em um domínio simbólico onde diversos mecanismos foram sendo construídos para justificar esta dominação. Estes mecanismos fundamentam-se em crenças e mitos criados a respeito da masculinidade e da feminilidade, ou seja, da dicotomia básica entre macho/fêmea, criando assim, diferentes papéis sociais a serem desempenhados por estes sexos. Sempre reforçando o ideal de superioridade masculina e delegando às mulheres papéis vistos como inferiores em nossa sociedade. ${ }^{10}$

Neste sistema lógico que tem a dicotomia como base, atribuímos qualidades aos sujeitos, assim, logos é comumente ligado à racionalidade, dominante, masculina e universal; enquanto pathos é atribuído às emoções relativas às fêmeas, dominadas, particulares.

\footnotetext{
${ }^{8}$ Iain Mackenzie cita Hélène Cixous quando esta se pergunta onde está representado o feminino dentro das oposições binárias: 'Em famosa crítica literária e filosófica, Cixous pergunta: ‘Onde está ela?’ nas seguintes oposições binárias que são recorrentes nos clássicos literários: 'atividade/passividade, sol/lua, cultura/natureza, $\mathrm{dia} /$ noite, pai/mãe, cabeça/coração, inteligível/sensível, logos/pathos', e finalmente 'homem/mulher'. Está claro, diz ela, que 'o pensamento sempre operou por meio da oposição... mediante oposições duais, hierarquizadas"' (CIXOUS apud MACKENZIE, Identidade, diferença e filosofia política, p. 158).

${ }^{9}$ LUGONES, "Rumo a um feminismo descolonial".

${ }^{10}$ COELHO, Gêneros desviantes: o conceito de gênero em Judith Butler, p. 79-80.
} 
É importante, neste ponto, pensarmos o que faz da voz masculina a voz dominante, ou melhor, a voz padrão. Segundo a filósofa ecofeminista norte-americana Karen J. Warren ${ }^{11}$, isto se dá por conta de uma estrutura conceitual patriarcal, na qual a mulher é identificada com a natureza e com o reino físico, enquanto o homem é identificado com a "humanidade", com o mental, nestes termos, o mental sempre é colocado como superior ao físico, criando assim, uma divisão dualística do mundo, "na qual os homens se consideram superiores por sua racionalidade e as mulheres são tidas como inferiores e associadas por eles aos sentimentos e a emoção" 12 .

É no campo discursivo que esta lógica ganha corpo. Assim, o próprio discurso se apresenta como campo de batalha, pois, segundo Teresa de Lauretis, não há uma realidade ontológica anterior ao discurso ${ }^{13}$. Não devemos nos esquecer da violência dentro dos atos discursivos e de que a história da língua não passa de uma história de violência ${ }^{14}$. Nas palavras de Monique Wittig: "A linguagem lança feixes de realidade sobre o corpo social, estampandoo e moldando-o violentamente" ${ }^{15}$. Segundo ela, a linguagem é um conjunto de atos repetidos ao longo do tempo, que produzem efeitos de realidade, estes que podem praticar uma violência material contra os corpos que eles afirmam organizar e interpretar. "Não há nada abstrato sobre o poder que as ciências e teorias têm para agir materialmente e efetivamente sobre nossos corpos e mentes, mesmo que o discurso que o produz seja abstrato"16.

O abismo profundo que separa de um lado a racionalidade e de outro as emoções foi constitutivo da história da Filosofia enquanto disciplina. Esta dualidade hierárquica deixou profundas marcas em nossa sociedade ocidental, grande parte, por sua marcação de gênero. A dualidade entre homens e mulheres também participa do princípio regulador hierárquico da linguagem. Nesta, a racionalidade, princípio básico da Filosofia disciplinar, destinada ao espaço público, era característica atribuída ao masculino; enquanto a emotividade, as emoções, eram destinadas ao espaço privado, restrito ao domínio do feminino.

O texto de Sara Ahmed, The Cultural Politics of Emotion, nos dá uma noção do significado do conceito "emoção". Ela nos coloca que certos atributos são sempre gendrados e, que a associação entre "passividade" e "paixão", nos mostra como "emoção" é tomada como inferior diante do "pensamento" e da "razão". Segundo ela, ser "emocional", neste sentido: "é ter um julgamento afetado: é ser mais reativo do que ativo, dependente ao invés de autônomo" ". Sua busca está em refletir sobre o fato de que "ser emocional" é característica atribuída a alguns corpos e não a outros (entendemos estes corpos geralmente como femininos). Ao colocar as emoções como categoria de análise, como trazendo-as à esfera política, Sara Ahmed nos dá espaço para pensarmos nossa própria atuação enquanto sujeitos políticos.

Ressaltamos que estas divisões duais e hierarquizadas que estruturam nosso modelo de pensar não são imanentes ao humano, mas a partir de suas repetições estilizadas, são

\footnotetext{
11 WARREN, Power and the Promise of Ecological Feminism, p. 214.

12 KUHNEN, "A ética do cuidado como teoria feminista", p. 2.

13 LAURETIS, A tecnologia do gênero.

${ }^{14}$ LECERCLE, The Force of Language.

15 WITTIG, "The Mark of Gender", p. 78, tradução nossa. No original: "Language casts sheaves of reality upon the social body, stamping it and violently shaping it'.

${ }_{16}$ WITTIG, The straight mind, p. 53, tradução nossa. No original: "There is nothing abstract about the power that sciences and theories have, to act materially, and actually upon our bodies and our minds, even if the discourse that produces it is abstract". 17 AHMED, The Cultural Politics of Emotion, p. 3, tradução nossa. No original: "To be emotional is to have one's judgement affected: it is to be reactive rather than active, dependent rather than autonomous".
} 
incorporadas, personificadas e subjetivadas. Não partimos aqui de um essencialismo que destina aos homens a razão e relega às mulheres as emoções. Para compreendermos este ponto, trazemos a categoria do cuidado a fim de analisarmos como estas diferenças são colocadas em nossa sociedade.

A categoria do cuidado adentra os campos teóricos a partir do trabalho da filósofa e psicóloga estadunidense Carol Gilligan. Em In a Different Voice, Gilligan discute a respeito das diferenças relativas ao desenvolvimento de meninos e meninas, colocando em questão os resultados obtidos por Lawrence Kohlberg, mostrando-nos que estes foram alcançados levando enquanto regra apenas o modelo masculino. Ao analisar as diferentes respostas de meninos e meninas, Gilligan percebe diferenças entre as vozes gendradas, pois, em pesquisas que utilizam a escala Kohlberg nas quais as mulheres são incluídas, estas se mostram menos elaboradas no desenvolvimento moral, ficando geralmente no terceiro estágio do desenvolvimento: "nesta fase, a moralidade é concebida em termos interpessoais e a bondade é equivalente a ajuda aos outros e desejo de lhes agradar"18.

Segundo a autora estas diferenças não se constituem como uma deficiência feminina, pelo contrário, em um modelo ético, a ética feminina mais pautada no cuidado com o outro do que em princípios lógicos universais, como observado na ética masculina, representa uma voz diferente àquela tida como dominante. Desta maneira, para Gilligan, seria apenas com a união destas duas vozes que poderíamos realmente pensar em uma ética universal.

Apesar das inúmeras críticas que Gilligan recebeu após a publicação de sua célebre obra em 1982, a teoria do cuidado ainda hoje gera inúmeros debates. A ideia de que as mulheres estariam ligadas intrinsecamente ao cuidado poderia fazer com que a categoria cunhada por Gilligan caísse dentro de uma ideia de essencialismo. Mas, segundo Zirbel, a explicação não é biológica, mas psicológica, e está intimamente ligada ao processo de individuação de meninos e meninas desde o nascimento, criando uma divisão psíquica de gênero. Esta afirma que:

uma das perspectivas (a masculina) teria sido delineada por Freud e amplamente adotada pela literatura psicológica como modelo ideal de individuação. A outra, pouco estudada, estaria amplamente representada no universo das mulheres. ${ }^{19}$

Muito embora a autora não deixe claro em sua obra, é importante destacar que, segundo ela, a cultura tem esse forte papel na construção do desenvolvimento moral.

Assim, devemos pensar sobre como a abertura da Filosofia (enquanto disciplina) em nosso país para os estudos de gênero e feminismos é bastante recente. Lembremos, por exemplo, que o GT de gênero da Associação Nacional de História, foi pensado no ano de 2001 e começou a existir formalmente no ano de 2002; enquanto nós, participantes da ANPOF, estamos apenas no segundo encontro do nosso GT. Esta demora em acatar gênero e os feminismos enquanto eixos temáticos, em grande parte, é devido ao próprio objeto da Filosofia disciplinar, a racionalidade ${ }^{20}$.

\footnotetext{
18 GILLIGAN, Teoria psicológica e desenvolvimento da mulher, p. 35.

19 ZIRBEL, Uma teoria político-feminista do cuidado, p. 44.

${ }^{20} \mathrm{E}$ importante reiterarmos aqui que não entendemos a divisão dual e hierarquizada que destina aos sujeitos masculinos a racionalidade e relega aos sujeitos femininos a emotividade como uma forma de essencialismo,
} 


\section{A exclusão das mulheres na Filosofia}

Como é intrínseco ao trabalho do "filósofo" a formação de conceitos "que não são eternos, absolutos, mas sempre abertos à ruptura, ao tempo, ao movimento, ao intempestivo, ao diálogo" 21 , buscamos aqui questionar a própria racionalidade atrás da "Razão". O que o intento racional havia deixado de lado (ou melhor, quem este intento abnegou)? O que fez a Filosofia historicamente selecionar seus problemas, privilegiando questões e discriminando outras? Nas palavras de Magali Menezes:

por que, por exemplo, a Filosofia resiste tanto em problematizar a história de opressão vivida pelas mulheres, construindo um discurso de exclusão e, muitas vezes, de desqualificação sistemática de mais da metade da espécie humana? ${ }^{22}$

A própria exclusão das mulheres na História da Filosofia já nos mostra a sua misoginia. Não há porque acreditarmos que as mulheres produziram sua exclusão de forma voluntária na história do conhecimento. Para Menezes ${ }^{23}$ o sujeito que produz e reproduz o conhecimento não é neutro, muito menos "ingênuo". Quem detém os meios de produção do conhecimento detém o controle dos discursos de poder. Segundo Foucault:

Temos antes que admitir que o poder produz saber (e não simplesmente favorecendo-o porque o serve ou aplicando-o porque é útil); que poder e saber estão diretamente implicados; que não há relação de poder sem constituição correlata de um campo de saber, nem saber que não suponha e não constitua ao mesmo tempo relações de poder. ${ }^{24}$

Saber e poder coexistem, são frutos de uma mesma alteridade. O discurso filosófico surge da batalha por poder, mirando a sua permanência na história. Lyotard cita Heráclito, "A guerra é pai de todos, rei de todos" 25 , é neste embate por permanência que se encontra a forja da Filosofia disciplinar. Para Menezes: "as unidades conquistadas pela Filosofia, (...) não surgem da harmonia, mas de uma disputa acirrada por uma verdade que permaneça na história" 26 . E novamente o campo do discurso entra em cena, pois o próprio discurso se coloca como o campo de batalha nesta luta por poder.

Devemos compreender que o poder e seus discursos estão intrinsecamente interligados com a construção de gênero. As normas de gênero têm ligação direta com os

pelo contrário, entendemos que as estruturas sociais possuem o poder de moldar os sujeitos, criando certos determinismos fictícios. Assim, quando falamos que o objeto da Filosofia é a racionalidade, não buscamos excluir as vozes femininas, mas apontamos que esta ideia de racionalidade é marcada e situada, que foi historicamente destinada a uma pequena parcela da população.

${ }^{21}$ MENEZES, Por que as mulheres e a Filosofia?, p. 122.

22 MENEZES, Por que as mulheres e a Filosofia?, p. 124.

${ }^{23}$ MENEZES, Por que as mulheres e a Filosofia?, p. 127.

${ }^{24}$ FOUCAULT, Vigiar e punir: nascimento da prisão, p. 27.

${ }^{25}$ LYOTARD, ¿Por qué filosofar?, p. 107.

26 MENEZES, Por que as mulheres e a Filosofia?, p. 125. 
limites discursivos do poder, são elas que ditam como e de quais maneiras podemos aparecer nos espaços públicos; como e qual a maneira que o público e privado são distinguidos; e como esta distinção é instrumentalizada em serviço de políticas sexuais. Segundo Judith Butler, as normas de gênero "não são apenas instâncias de poder; e elas não refletem apenas relações de poder mais amplas; eles são uma maneira do poder agir" ${ }^{27}$.

Em toda a história do ocidente, falar nos espaços públicos nunca foi algo que as mulheres puderam fazer, pelo contrário, esta é uma prática que define a masculinidade enquanto gênero. A voz das mulheres sempre ameaçou subverter a estabilidade social e política do Estado como um todo. Uma herança trazida desde o período clássico a qual, segundo Mary Beard: "nos forneceu um poderoso gabarito para pensar a respeito do discurso público e decidir o que se define como oratória boa ou ruim, persuasiva ou não, e a qual discurso deve ser dado espaço para ser ouvido" 28 .

\section{Antígona e o silenciamento das mulheres}

Encontramos na história e na literatura clássica diversos exemplos que poderíamos citar aqui de como a voz das mulheres foi silenciada. Entre estes tomamos a figura de Antígona, personagem de Sófocles que desafiou as leis do Estado em nome daquilo que considerava mais importante, seus laços de sangue. Segundo o filósofo alemão Friedrich Hegel, é a feminilidade de Antígona que "perverte o universal, transformando o Estado em propriedades e ornamentos para a família, decorando a família com a parafernália do Estado, tecendo bandeiras e mantas a partir do aparato do Estado" 29 . Ao ir contra o édito de Creonte, Antígona retira o caráter universal das leis deslocando o político para a propriedade privada, esta que é domínio do feminino. Creonte diz que enquanto ele governar nenhuma mulher fará as leis de Tebas, e se não a punir por seu ato perderá seu papel de homem o qual ela tomaria. Creonte diz:

Esta já se mostrou insolente/ ao transgredir as leis estabelecidas. / Insolência renovada é orgulhar-se/ e rir cometida a transgressão. / Agora, entretanto, homem não serei eu, / [homem será ela,/ se permanecer impune tamanho atrevimento. ${ }^{30}$

Assim, percebemos que o ato de rebeldia de Antígona está justamente em sua fala, ela não só fala, mas fala no espaço que é público, este destinado apenas aos homens, onde as mulheres apenas devem ouvir. Segundo Mary Hawkesworth:

Em sua Antígona, Sófocles apresenta uma cultura que não é apenas um espaço físico gendrado, destinando às mulheres as profundezas do espaço doméstico

\footnotetext{
${ }^{27}$ BUTLER, "Performativity, precariety and sexual politics", p. 2, tradução nossa. No original: "So these norms are not only instances of power; and they do not only reflect broader relations of power; they are one way that power operates".

${ }^{28}$ BEARD, Mulheres e poder: um manifesto, não paginado.

${ }^{29}$ BUTLER, O clamor de Antígona: parentesco entre a vida e a morte, p. 60.

30 SÓFOCLES, Antígona, [480].
} 
enquanto confere aos homens o mundo público, mas também a virtude gendrada. ${ }^{31}$

O falar se torna ato masculino e o ouvir feminino, segundo Butler:

Ouvir é figurado como um tipo de entrega, uma atividade feminina que o transforma numa mulher. [...] E isso nos diz que o seu gênero pode ser facilmente desfeito caso ele se torne suscetível àquilo que ouve. ${ }^{32}$

$\mathrm{Na}$ tragédia de Sófocles fica claro que muito mais do que ser punida por seu ato, Antígona é punida por seu ato de fala, que, segundo Luce Irigaray: "Ao menos em voz alta, dessa forma, ela se torna a cúmplice voz do povo, dos escravos, daqueles que apenas sussurram sua revolta contra os seus senhores secretamente"33, assim, Antígona é quem não tem voz, mas que se atreve a roubar o lugar de fala, se fazer ouvida é onde se encontra seu crime.

Antígona é apenas mais um exemplo de tantas mulheres que foram silenciadas durante a história, ou que então, pagaram com sua própria vida por desafiar falar no espaço público. Os poucos relatos de mulheres que ousaram falar neste espaço não são tomados como exemplos a serem seguidos, ou como detentoras de algum poder, mas sim como agressoras. Desta forma, Beard afirma que as mulheres não são vistas como totalmente pertencentes às estruturas do poder ${ }^{34} \mathrm{e}$, consequentemente, seus discursos não adentram as esferas em que o poder está.

\section{O feminismo e a disputa pelos espaços de poder}

Durante quase toda a história da humanidade as mulheres foram impedidas de falar no espaço público, este que em nossa sociedade é o espaço privilegiado de poder. Isto não significa que nenhuma mulher conseguiu este feito, mas as poucas que conseguiram, pagaram um preço muito alto por isso. Podemos tomar como exemplo autoras como Olympe de Gouges (Déclaration des droits de la femme et de la citoyenne, 1791) e Mary Wollstonecraf (A Vindication of the Rights of Woman with Strictures on Moral and Political Subjects, 1792) que já no século XVIII, de alguma forma, perceberam e denunciaram a dominação masculina. Estas autoras são frequentemente mencionadas como precursoras do feminismo, mas é apenas no século XX que este movimento ganha maior força e visibilidade, caracterizando-se como um movimento social com diferentes reivindicações relacionadas à realidade das mulheres.

Já no final do século XIX as mulheres lutavam por melhores condições de trabalho nas fábricas, por igualdade nos direitos contratuais e à propriedade privada, pelo direito ao divórcio e pelo fim dos casamentos arranjados, mas principalmente pela busca por direitos políticos, especialmente o direito ao sufrágio pelas mulheres. As sufragistas foram ouvidas e

\footnotetext{
${ }^{31}$ HAWKESWORTH, "A semiótica de um enterro prematuro: o feminismo em uma era pós-feminista”, p. 758.

32 BUTLER, O clamor de Antígona: parentesco entre a vida e a morte, p. 121.

33 IRIGARAY, Speculum of the other woman, p. 218, tradução nossa. No original: "At the least out loud. In this way, she becomes the voice, the accomplice of the people, the slaves, those who only whisper their revolt against their masters secretly".

${ }^{34}$ BEARD, Mulheres e poder: um manifesto, não paginado.
} 
conseguiram o direito ao voto em 1919 nos Estados Unidos, 1928 no Reino Unido e em 1932 no Brasil. O direito ao sufrágio universal foi um marco nas lutas feministas, após sua conquista o movimento perde sua força retomando novamente apenas na década de 60 lutando por uma maior igualdade entre mulheres e homens, pelo direito das mulheres a sua autonomia e à integridade de seus corpos. É principalmente na segunda metade do século passado que o feminismo encontra na academia um solo profícuo para discussão. Como movimento o feminismo conseguiu diversos avanços na realidade social que vivemos, mas além de ser um movimento social as lutas feministas se caracterizam pela concordância entre teoria e prática, sendo assim, também, um movimento tanto filosófico quanto político.

Mas a história das mulheres no espaço privilegiado de conhecimento na nossa sociedade, a universidade, ainda é bastante recente. Os Estados Unidos foi o primeiro país a permitir a educação superior para mulheres, mesmo que de forma segregada. Para Bezerra: "a entrada das mulheres na universidade aconteceu primeiramente nos Estados Unidos no ano de 1837, com a criação de universidades exclusivas para as mulheres. É no estado de Ohio que surge a primeira universidade feminina o women's college" ${ }^{35}$. As brasileiras precisaram esperar quase 50 anos para que pudessem sentar nos bancos universitários em nosso país. Segundo Beltrão e Alves:

o decreto imperial que facultou à mulher a matrícula em curso superior data de 1881. Todavia, era difícil vencer a barreira anterior, pois os estudos secundários eram essencialmente masculinos, além de caros e os cursos normais não habilitavam as mulheres para as faculdades. ${ }^{36}$

Assim, mesmo que legalmente as mulheres pudessem estar nas universidades desde o século XIX, na prática, por inúmeros fatores, o número de estudantes mulheres ainda era muito baixo.

Atualmente, em nosso país, as mulheres são a maioria nos bancos universitários, e este número é também refletido nos cursos de pós-graduação. Dados extraídos da plataforma sucupira da CAPES mostram que em 2015175.419 mulheres estavam matriculadas ou foram tituladas em cursos de mestrado e doutorado, enquanto os homens somam 150.236, uma diferença de aproximadamente 15\%. ${ }^{37}$ Mas, Carolina Araújo nos mostra em seu artigo “Mulheres na Pós-Graduação em Filosofia no Brasil - 2015” que na Filosofia, a situação das mulheres é diferente. Logo no resumo de seu trabalho ela expressa a situação das mulheres em números:

Das 4.437 pessoas, entre docentes e discentes, que compõem a comunidade analisada, $27 \%$ são mulheres e $73 \%$ são homens, o que contrasta com a proporção entre os egressos da graduação em Filosofia, em que as mulheres são 38,4\% e os homens 61,6\%. Em analisando as proporções entre homens e mulheres nos vários estágios da carreira da Pós-Graduação em Filosofia, começando com os concluintes da graduação $(38,4 \%)$ e terminando com os professores permanentes de Programas de Pós-Graduação (19,95\%), o

\footnotetext{
${ }^{35}$ BEZERRA, "Mulher e universidade: a longa e difícil luta contra a invisibilidade", p. 3.

${ }^{36}$ BELTRÃO e ALVES, "A reversão do hiato de gênero na educação brasileira no século XX”, p. 128.

${ }^{37}$ CAPES, "Mulheres são maioria na pós-graduação brasileira".
} 
relatório conclui que a proporção de mulheres diminui em $48 \%$, enquanto a de homens aumenta em $29,95 \%$ (de $61,6 \%$ na base para $80,05 \%$ no topo). A conclusão é de que uma mulher tem aproximadamente 2,5 vezes menos chance do que um homem de chegar ao topo desta carreira profissional. ${ }^{38}$

Os dados analisados por Carolina Araújo mostram que ainda é muito pequena a participação das mulheres na construção do pensamento filosófico em nosso país. Apesar de estes dados nos darem números preocupantes, não podemos deixar de comemorar os pequenos avanços conquistados com muito esforço e dedicação de mulheres que foram pioneiras na construção de uma Filosofia brasileira.

\section{Conclusão}

Assim, quando os discursos de sujeitos femininos aos poucos vão tomando espaço e adentrando no campo discursivo da Filosofia disciplinar, trazem consigo suas experiências subjetivadas. Experiências estas marcadas por gênero e este gênero marcado pela lógica discursiva dualizada e hierárquica, que entende o discurso destes sujeitos femininos como intrinsecamente ligado às emoções. A partir destas experiências o conhecimento científico se abre a diferentes possibilidades, dando cada vez mais espaço às subjetividades, às emoções e aos afetos.

Ao apostar apenas na racionalidade, deixando de lado o caráter emocional, a Filosofia disciplinar abandonou uma de suas partes constitutivas, o espanto, o ato de admirar-se com o mundo. Desta maneira, ao abrir-se gradualmente (e não sem resistências) aos estudos feministas, a Filosofia dá novamente espaço às emoções, abrindo-se à possibilidade de afetarse com o mundo.

Portanto, defendemos aqui que a abertura da Filosofia disciplinar aos feminismos, abriu também a possibilidade de que outros discursos adentrassem ao modelo de se fazer Filosofia na academia. Discursos estes repletos de subjetividades, emoções, afetos e cuidado. Defendemos também que uma Filosofia para ser completa necessita da união de vozes complementares, de formas diferentes de encarar e admirar-se com o mundo, de abrir-se ao espanto. Assim, abrindo-se a novos discursos, suas subjetividades e interseccionalidades, podemos vislumbrar cada vez mais uma academia inclusiva e plural, em que diferentes vozes possam ser ouvidas e onde o conhecimento científico possa ir além dos marcadores de gênero, raça e classe.

\section{Referências bibliográficas}

AHMED, Sara. The Cultural Politics of Emotion. Edinburgh: Edinburgh University Press, 2004.

ARAÚJO, Carolina. “Mulheres na Pós-Graduação em Filosofia no Brasil - 2015”. Relatório Anpof. São Paulo: ANPOF, $2016 . \quad$ Disponível em: http://anpof.org/portal/images/Documentos/ARAUJOCarolina_Artigo_2016.pdf

38 ARAÚJO, "Mulheres na Pós-Graduação em Filosofia no Brasil - 2015”, p. 1. 
BEAUVOIR, Simone. O segundo sexo: a experiência vivida. Vol. 2. Tradução de Sérgio Milliet. $2^{\mathrm{a}}$ ed. São Paulo: Difusão Europeia do Livro, 1967.

O segundo sexo: mitos e fatos. Vol. 1. Tradução de Sérgio Milliet. $4^{a}$ ed. São Paulo: Difusão Europeia do Livro, 1970.

BEARD, Mary. Mulheres e poder: um manifesto. Tradução de Celina Portocarrero. São Paulo: Planeta do Brasil, 2018.

BELTRÃO, Kaizô Iwakami; ALVES, José Eustáquio Diniz. "A reversão do hiato de gênero na educação brasileira no século XX”. Cadernos de Pesquisa, v. 39, n. 136, pp. 125-156, jan./abr. 2009.

BEZERRA, Nathalia. "Mulher e universidade: a longa e difícil luta contra a invisibilidade". Anais da Conferência Internacional sobre os Sete Saberes, 2010, Fortaleza. Fortaleza: UECE, 2010, pp. 1-8.

BURNET, John. Early Greek Philosophy. 3. ed. Londres: A \& C Black, 1920.

BUTLER, Judith. "Performativity, precariety and sexual politics". Revista de Antropología Iberoamericana. Volume 4, número 3. Diciembre 2009. Madrid: Antropólogos Iberoamericanos, pp. 1-13.

BUTLER, Judith. O clamor de Antígona: parentesco entre a vida e a morte. Tradução de André Cechinel. Florianópolis: UFSC, 2014.

CAPES. "Mulheres são maioria na pós-graduação brasileira". Portal do Governo Brasileiro. Brasília, 03 março de 2017. Disponível em: https://www.gov.br/capes/ptbr/assuntos/noticias/mulheres-sao-maioria-na-pos-graduacao-brasileira. Acesso em: 27 maio de 2020 .

CIXOUS, Hélène. The Laugh of the Medusa. Chicago: The University of Chicago Press, 1976.

COELHO, Mateus Gustavo. Gêneros desviantes: o conceito de gênero em Judith Butler. 2018. 101 f. Dissertação (Mestrado) - Curso de Filosofia, Centro de Ciências Humanas, Universidade Federal de Santa Catarina, Florianópolis, 2018.

CORNFORD, F. M. From Religion to Philosophy: a Study in the Origins of Western Speculation. New York: Harper Torchbooks, 1957.

FOUCAULT, Michel. Vigiar e punir: nascimento da prisão. 27ª ed. Petrópolis: Vozes, 1987.

GILLIGAN, C. Uma voz diferente. Psicologia da diferença entre homens e mulheres da infância à fase adulta. Rio de Janeiro: Rosa dos Tempos, 1982.

Teoria psicológica e desenvolvimento da mulher. Lisboa: Fundação Calouste Gulbenkian, 1997. 
HAWKESWORTH, Mary. "A semiótica de um enterro prematuro: o feminismo em uma era pós-feminista”. Rev. Estud. Fem., Florianópolis, volume 14, número 3, set./dez. 2006, pp. 737-763.

IRIGARAY, Luce. Speculum of the other woman. New York: Cornell University Press, 1985.

KUHNEN, T. A. "A ética do cuidado como teoria feminista". In: Anais do III Simpósio Gênero e Políticas Públicas. Londrina, 2014.

LAURETIS, Teresa de. "A tecnologia do gênero". Tradução de Suzana Funck. In: HOLLANDA, Heloisa Buarque de (Org.). Tendências e impasses - o feminismo como crítica da cultura. Rio de Janeiro: Rocco, 1994, pp. 206-242.

LECERCLE, Jean-Jacques; RILEY, Denise. The Force of Language. New York: Palgrave Macmillan, 2005.

LUGONES, María. "Rumo a um feminismo descolonial". Estudos feministas, Florianópolis, 22(3), set./dez. 2014, pp. 935-952.

LYOTARD, Jean-François. A condição pós-moderna. $12^{\mathrm{a}}$ ed. Rio de Janeiro: José Olympio, 2009. - ¿Por qué filosofar?. Barcelona: Paidós, 1996.

MACKENZIE, Iain. "Identidade, diferença e filosofia política". In: Política: conceitos-chave em filosofia. Porto Alegre: ArtMed, 2011, pp. 151-175.

MENEZES, Magali Mendes de. "Por que as mulheres e a Filosofia?". In: CARVALHO, Marie Jane Soares; ROCHA, Cristianne Maria Fammer (Org.). Produzindo gênero. Encontro Nacional da Rede Brasileira de Estudos e Pesquisas Feministas. Porto Alegre: Sulina, 2004, pp. 122-127.

PLATÃO. Diálogos: Teeteto - Crátilo. Tradução de Carlos Alberto Nunes. Belém: UFPA, 1973.

SÓFOCLES. Antígona. Tradução de Donaldo Schüler. Porto Alegre: L\&PM, 2016.

VERNANT, Jean-Pierre. « Do mito à razão ». In: VERNANT, Jean-Pierre. Mito e pensamento entre os gregos: estudos de psicologia histórica. $2^{\mathrm{a}}$ ed. Rio de Janeiro: Editora Paz e Terra, 1988. Cap. 7, pp. 441-474.

WITTIG, Monique. “The Mark of Gender”. Feminist Issues, Fall, 1985, pp. 3-12.

. "The straight mind". In: FERGUSON, Russell et al. (Ed.). Out There: Marginalization and Contemporary Culture. Cambridge: The MIT Press, 1995, pp. 51-57.

WARREN, K. J. "The Power and the Promise of Ecological Feminism". In: ZIMMERMANN, Michael et al. (Org.). Environmental Philosophy. Upper Saddle River: Prentice Hall, 1998, pp. 325-344. 
ZIRBEL, Ilze. Uma teoria político-feminista do cuidado. 2016. 260 f. Tese (Doutorado) - Curso de Filosofia, Centro de Ciências Humanas, Universidade Federal de Santa Catarina, Florianópolis, 2016. 